\title{
Analisa Konsentrasi Logam Cd Pada Rhizophora.Sp Menggunakan Metode AAS Di Kawasan Pelabuhan Gilimanuk Jembrana Bali
}

\author{
${ }_{1,2}^{1}$ Karel Yesaya Mbaba, ${ }^{2}$ Ida Bagus Made Suryatika, ${ }^{3}$ I Gusti Agung Putra Adnyana \\ ${ }^{1,2,3}$ Program Studi Fisika, Fakultas Matematikadan Ilmu Pengetahuan Alam, Universitas \\ Udayana, Jimbaran, Bali, 80361 \\ Email Korespondensi: mbabakarel14@gmail.com ; suryatikabiofisika@yahoo.com ; \\ igaadnyana70@yahoo.com
}

\begin{tabular}{|c|c|}
\hline Article Info & Abstract \\
\hline $\begin{array}{l}\text { Article History } \\
\text { Received: August } \\
\text { Revised: November } \\
\text { Published: December } \\
\text { Keywords } \\
\text { Mangrove Plants, Cu } \\
\text { Metal, AAS, Gilimanuk } \\
\text { Port }\end{array}$ & $\begin{array}{l}\text { In this study, research was conducted on the analysis of Cu concentrations in } \\
\text { mangrove plants (Rhizophora.sp) using the Atomic Absorbtion } \\
\text { Spectrophotometry (AAS) method in the Gilimanuk Jembrana port area of Bali. } \\
\text { The research was conducted on June 23, } 2019 \text { until July 28, } 2019 \text { in the } \\
\text { Faculty of Mathematics and Natural Sciences, Udayana University. The } \\
\text { method used is Atomic Absorption Spectrophotometry (AAS), a principle that is } \\
\text { based on the process of absorption of energy by atoms that are at the level of } \\
\text { basic energy (groundstate). The sample used is in the form of root stems and } \\
\text { leaves of mangroves that are cleaned and destroyed in advance, because AAS } \\
\text { can only analyze the material in the form of liquid. The results of the analysis } \\
\text { with AAS are the Cd metal content at Gilimanuk port has exceeded the } \\
\text { threshold of the quality standard that is in accordance with sea water quality } \\
\text { standards according to Environmental Decree Number: KEP-MEN LH No.51 I } \\
\text { Men KLH / 2004 Cd threshold for tourism marine is 0,002 ppm and for biota is } \\
0,001 \text { ppm, while mangrove is included in marine tourism with a threshold of } \\
0,002 \text { ppm. }\end{array}$ \\
\hline Informasi Artikel & Abstrak \\
\hline $\begin{array}{l}\text { Sejarah Artikel } \\
\text { Diterima: September } \\
\text { Direvisi: November } \\
\text { Dipublikasi: Desember } \\
\text { Kata kunci } \\
\text { Tumbuhan Bakau, Logam } \\
\text { Cu, AAS, Pelabuhan } \\
\text { Gilimanuk }\end{array}$ & $\begin{array}{l}\text { Pada penelitian ini, dilakukan penelitian tentang analisa konsentrasi Cu pada } \\
\text { tanaman bakau (Rhizophora.sp) menggunakan metode Atomic Absorbtion } \\
\text { Spektrophotometri (AAS) di kawasan pelabuhan Gilimanuk Jembrana Bali. } \\
\text { Penelitian di lakukan pada } 23 \text { Juni } 2019 \text { sampai dengan } 28 \text { Juli } 2019 \text { di } \\
\text { laboratorium FMIPA Universitas Udayana. Metote yang di gunakan adalah } \\
\text { Atomic Absorbtion Spektrophotometri ( AAS ) yaitu prinsip yang didasarkan } \\
\text { pada proses penyerapan energi oleh atom-atom yang berada pada tingkat } \\
\text { tenaga dasar (groundstate). Sampel yang di pakai berupa akar batang dan daun } \\
\text { bakau yang di bersihkan dan di destruksi terlebih dahulu, karna AAS hanya } \\
\text { bisa menganalisa bahan dalm bentuk cairan. Hasil analisa dengan AAS adalah } \\
\text { kandungan logam Cd di pelabuhan Gilimanuk telah melebihi ambang batas dari } \\
\text { baku mutu yang di tetapkaan sesuai pedoman baku mutu air laut menurut } \\
\text { Keputusan Lingkungan Hidup Nomor: KEP-MEN LH No.51/Men KLH/2004 } \\
\text { ambang batas Cd untuk wisata bahari adalah } 0,002 \text { ppm dan untuk biota adalah } \\
0,001 \text { ppm, sedangkan bakau termasuk ke dalam wisata bahari dengan ambang } \\
\text { batas } 0,002 \text { ppm. }\end{array}$ \\
\hline
\end{tabular}

\section{PENDAHULUAN}

Salah satu pencemaran yang berpotensi menurunkan dan merusak sumber daya lingkungan adalah logam berat. Logam berat adalah bahan pencemar yang berbahaya karena bersifat toksik jika terdapat dalam jumlah besar dan mempengaruhi berbagai aspek dalam perairan, 
baik secara biologis maupun ekologis. Keberadaan logam berat di perairan laut dapat berasal dari berbagai sumber, antara lain dari kegiatan pertambangan, rumah tangga, limbah pertanian dan buangan industri (Rochyatun dkk, 2006). Kandungan logam berat yang meningkat dalam perairan (air dan sedimen) akan mempengaruhi kehidupan organisme di perairan tersebut. Logam berat dapat masuk ke dalam sistem rantai makanan dan melalui proses biomagnifikasi akan terakumulasi (Darmono, 2010). Peningkatan kadar logam berat pada air laut akan mengakibatkan logam berat yang semula dibutuhkan untuk proses metabolisme berubah menjadi racun bagi organisme laut. Hal ini berkaitan dengan sifat logam berat yaitu sulit terurai sehingga mudah terakumulasi dalam lingkungan perairan dan keberadaannya secara alami sulit terurai (Ika, T \& Irwan S, 2012).

Bakau merupakan salah satu kelompok tumbuhan yang terdapat dalam kawasan pantai yang dapat berfungsi untuk menyerap bahan-bahan pencemaran termasuk logam berat sehingga dapat dijadikan bioindikator. Melalui akarnya, vegetasi ini menyerap logam-logam berat yang terdapat pada sedimen (Amin, 2001). Bakau bagi manusia juga bermanfaat baik secara langsung dan tidak langsung. Manfaatnya dapat digunakan sebagai bahan papan dan pangan. Secara ekologi, ekosistem bakau juga berfungsi sebagai perangkap sedimen dan mencegah erosi serta penstabil bentuk darat di daerah estuari. Sedangkan bagi hewan laut seperti ikan kecil, kepiting, udang dan hewan lainnya ialah sebagai tempat berlindung dan sebagai tempat mencari makan yaitu seperti lumut plankton dan fitoplankton (Hamzah dan Setiawan, 2010).

Pesisir Gilimanuk Jembrana merupakan daerah yang dipenuhi berbagai aktivitas, antara lain industri, pelabuhan, pertanian, serta pemukiman. Perairannya digunakan untuk kegiatan pelayaran dan penangkapan ikan. Kompleksnya aktivitas di pantai tersebut tentunya sangat berpengaruh terhadap keseimbangan ekosistem. Antara lain masuknya limbah kedalam ekosistem di sekitarnya. Kadmium (Cd) merupakan salah satu logam yang dapat merusak lingkungan. Hal ini dikarenakan logam tersebut termasuk logam non-essensial sehingga keberadaannya tidak memberikan pengaruh baik (Cutra, 2013). Adanya cemaran tersebut dikhawatirkan merusak ekosistem dengan mengganggu pertumbuhan bakau, sehingga tidak dapat dimanfaatkan secara ekologi maupun ekonomi. Ambang batas logam Cd berdasarkan pedoman baku mutu air laut menurut Keputusan Lingkungan Hidup Nomor: KEP-MEN LH No.51/Men KLH/2004 ambang batas Cd untuk wisata bahari adalah 0,002 ppm dan untuk biota adalah 0,001 ppm, sedangkan bakau termasuk ke dalam wisata bahari dengan ambang batas 0,002 ppm (Setiawan, 2013). Tercemarnya tubuhan bakau dengan logam berat, dapat berpengaruh terhadap nilai manfaat yang dapat digunakan antara lain bahan yang dijadikan pangan menjadi tidak layak konsumsi karena sudah tercemar (Cutra, 2013).

Penelitian ini dilakukan untuk menganalisis kandungan logam berat yang terdapat pada akar, batang dan daun bakau. Serta untuk mengetahui apakah vegetasi tersebut dapat dijadikan indikator pencemaran logam berat pada tanaman bakau di kawasan perairan Gilimanuk Jembrana Bali menggunakan metode AAS (Atomic Absorbtion Spektrophotometri). Metode AAS adalah teknik analisis kuantitatif spektrofometri yang di dasarkan pada sinar atom untuk menganalisis sebuah logam dan kandungannya (Purba, 2017). 


\section{METODE}

Alur penelitian yang dilakukan oleh penulis dapat digambarkan dalam skema berikut.

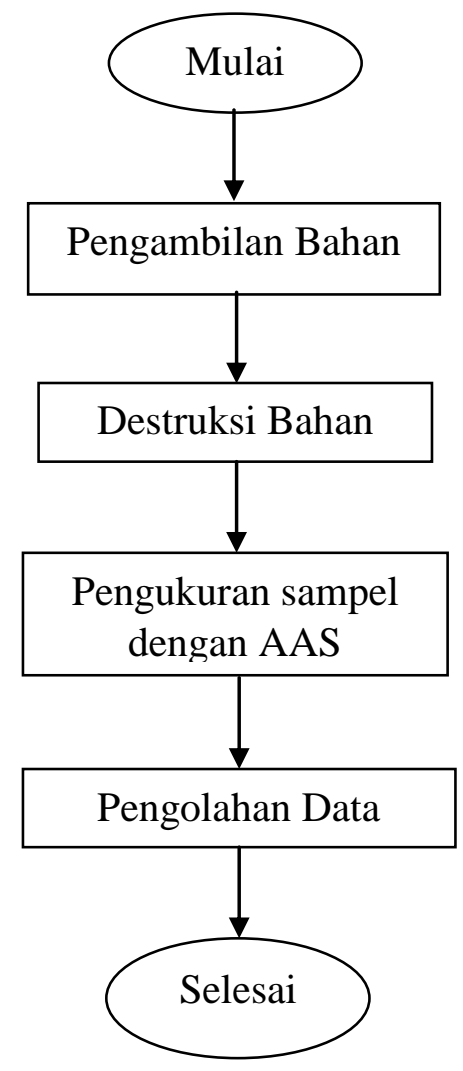

Gambar 1. Skema penelitian

Bahan di ambil terlebih dahulu di pelabuhan Gilimank, Jembrana, Bali berupa akar, batang dan daun sabanyak tujuh sampel setiap bagian. Kemudia sampel di bersihkan dan di potong kecil-kecil untuk di destruksi. Destruksi bahan menggunakan asam nitrat, asam sulfat dan aquades yang akan menghasilkan bahan dalam bentuk cairan seperti pada gambar 2. Setelah bahan di destruksi, lakukan pengukuran dengan AAS. Data hasil pengukuran AAS di olah lebih lanjut dalam bentuk tabel dan grafik untuk di lihat perbandingan kandungan logam dari masing-masing sampel.

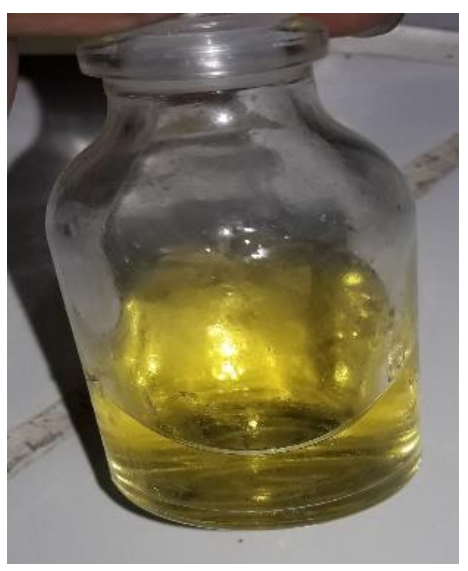

Gambar 2. Hasil destruksi bahan 


\section{HASIL DAN PEMBAHASAN}

Hasil konsentrasi pada perhitungan dengan AAS setiap sampel di rata-ratakan menurut bagian dari sampel tersebut. Contoh pada hasil analisa konsentrasi logam Cd pada akar bakau sampel pertama terdapat lima kali pengukuran, pengukuran pertama menghasilkan kandungan logam sebesar 0,7461 ppm, pengukuran ke dua sebesar 0,4864 ppm, pengukuran ke tiga sebesar 0,5936 ppm, pengukuran ke empat sebesar 0,0193 ppm, dan pada pengukran ke lima sebesar 0,8105 ppm. Apabila ke lima hasil analisa tersebut di rata-ratakan maka akan menghasilkan konsentrasi sebesar 0,5312 ppm.

Tabel 1. Konsentrasi logam Cd setiap sampel setelah di lakukan perhitungan rata- rata dan standar

\begin{tabular}{|c|c|c|c|c|c|c|c|}
\hline Sampel & $\begin{array}{l}\text { Bagian } \\
\text { sampel }\end{array}$ & & Pengu & $\begin{array}{r}\text { Iran ke } \\
(\mathrm{ppm})\end{array}$ & $2,3,4,5$ & & $\begin{array}{c}\bar{X} \\
(\mathrm{ppm})\end{array}$ \\
\hline \multirow{3}{*}{ Sampel 1} & Akar & 0,7461 & 0,4864 & 0,5936 & 0,0193 & 0,8105 & 0,5312 \\
\hline & Batang & 0,9677 & 0,8677 & 0,5317 & 1,4920 & 0,9010 & 0,9520 \\
\hline & Daun & 0,9892 & 0,7009 & 1,9948 & 0,3672 & 0,8939 & 0,9892 \\
\hline \multirow{3}{*}{ Sampel 2} & Akar & 1,3609 & 1,2299 & 0,7080 & 0,5650 & 0,0789 & 0,7885 \\
\hline & Batang & 1,8137 & 0,8986 & 1,2966 & 1,4777 & 1,4610 & 1,3895 \\
\hline & Daun & 0,7128 & 0,3220 & 0,9677 & 1,4753 & 0,9201 & 0,8796 \\
\hline \multirow{3}{*}{ Sampel 3} & Akar & 0,9749 & 0,9082 & 0,6866 & 0,8486 & 0,9677 & 0,8772 \\
\hline & Batang & 0,2552 & 1,4610 & 0,7819 & 0,4125 & 0,8391 & 0,7499 \\
\hline & Daun & 0,9844 & 1,2037 & 1,4991 & 0,7747 & 0,9677 & 1,0859 \\
\hline \multirow{3}{*}{ Sampel 4} & Akar & 0,7318 & 0,9320 & 0,5912 & 1,2537 & 1,1369 & 0,9291 \\
\hline & Batang & 1,1536 & 1,0654 & 0,6365 & 1,3371 & 1,3371 & 1,1059 \\
\hline & Daun & 1,4944 & 0,9296 & 0,7009 & 1,0083 & 0,4697 & 0,9206 \\
\hline \multirow{3}{*}{ Sampel 5} & Akar & 0,0897 & 0,0831 & 1,0987 & 0,0881 & 0,0831 & 0,2885 \\
\hline & Batang & 0,5197 & 0,2219 & 0,2171 & 0,2100 & 0,5031 & 0,3344 \\
\hline & Daun & 0,3720 & 0,5126 & 0,8917 & 0,8414 & 0,7128 & 0,6661 \\
\hline \multirow{4}{*}{ Sampel 6} & Akar & 1,2918 & 0,2981 & 0,5126 & 0,2552 & 1,4706 & 0,76567 \\
\hline & Batang & 0,1099 & 0,8414 & 1,4991 & 0,5102 & 0,6079 & 0,7137 \\
\hline & Daun & 0,1551 & 0,9940 & 0,1551 & 0,7485 & 0,4769 & 0,5059 \\
\hline & Akar & 0,5960 & 0,5769 & 0,4244 & 0,7247 & 0,4959 & 0,5636 \\
\hline
\end{tabular}




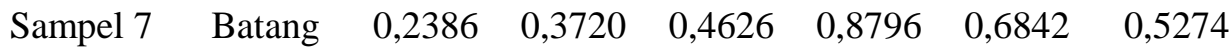

$\begin{array}{lllllll}\text { Daun } & 0,4077 & 1,0059 & 1,0726 & 0,2957 & 0,6484 & 0,6860\end{array}$

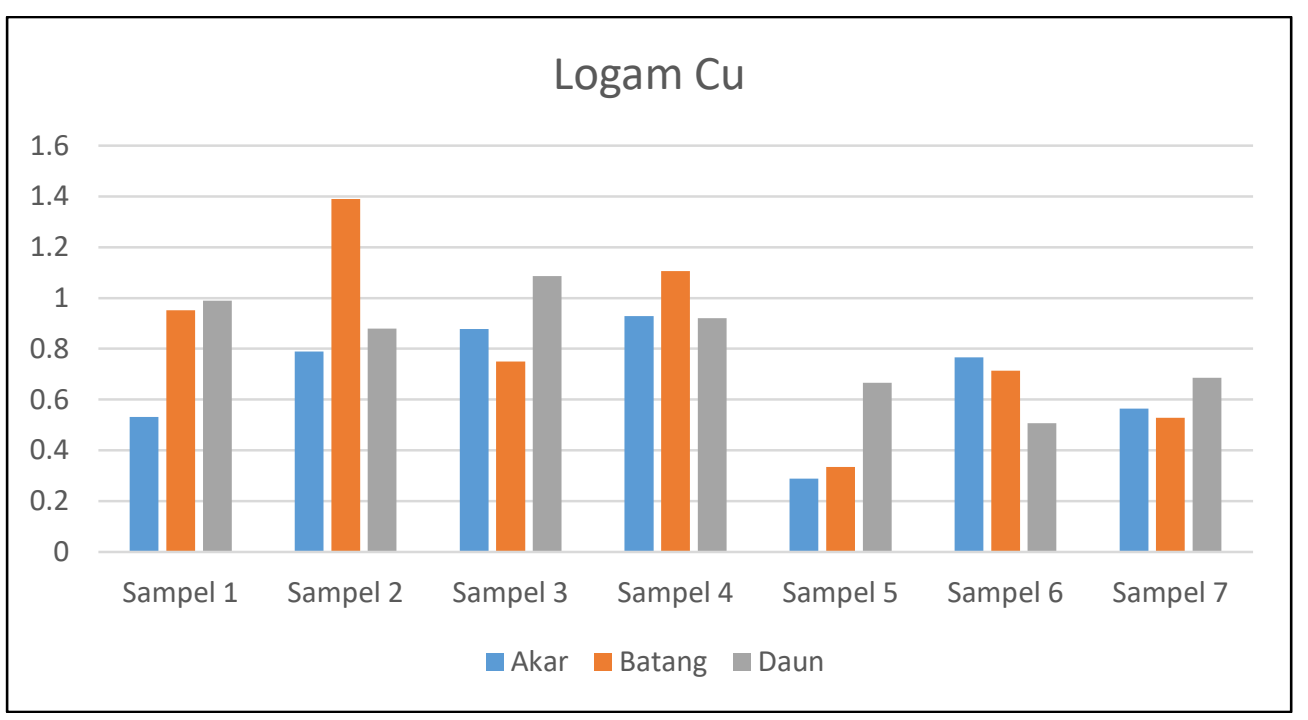

Gambar 3. Grafik perbandingan tingkat kandungan logam masing-masing sampel

Pada Tabel 1 dan Gambar 3 menampilkan perbandingan kandungan logam $\mathrm{Cd}$ pada akar, batang dan daun bakau. Kandungan logam Cd pada tanaman bakau tertinggi bagian akar tertinggi pada sampel ke empat yaitu sebesar 0,9291 ppm, dan berturut-turut sampel ke tiga, enam, dua, tujuh, satu dan lima. Pada bagian batang kandungan logam Cd tertinggi terdapat pada sampel ke dua yaitu sebesar 1,3895 ppm, dan berturut-turut pada sampel empat, satu, tiga, enam, tujuh dan lima. sedangkan kandungan logam $\mathrm{Cd}$ pada bagian daun tumbuhan tertinggi terdapat pada sampel ke tiga yaitu sebesar $1,0859 \mathrm{ppm}$, dan berturut-turut sampel satu, empat, dua, tujuh, lima dan enam. Besarnya kandungan logam $\mathrm{Cd}$ ini di sebabkan oleh limbah kapal yang ada di sekitar pelabuhan serta juga di sebabkan oleh kegiatan warga yang membuang sampah dan limbah rumah tangga ke laut tiap harinya. Berdasarkan hasil analisa kandungan logam $\mathrm{Cd}$ yang di peroleh jika di bandingkan dengan baku mutu logam Cd pada bakau yaitu 0,02 ppm, maka dapat di simpulkan bahwa kandungan logam Cd di sekitar pelabuhan Gilimanuk telah melebihi ambang batas.

\section{KESIMPULAN}

Berdasarkan hasil penelitian kandungan logam Cd pada tanaman bakau di pelabuhan Gilimanuk Jembrana Bali memiliki nilai konsentrasi terbesar pada akar sebesar 0,9291 ppm, batang 1,3895 ppm dan daun 1,0859 ppm, dengan hasil tersebut maka dapat disimpulkan bahwa konsentrasi logam Cd pada tanaman bakau di pelabuhan Gilimanuk melebihi baku mutu yang di anjurkan yaitu sebesar 0,02 ppm.

\section{SARAN}

Berdasarkan hasil analisis kandungan logam $\mathrm{Cu}$ pada tanaman bakau di pelabuhan Gilimanuk dengan penggunakan AAS maka di sarankan agar penduduk di daerah pesisir pelabuhan Gilimanuk agar libih memperbanyak populasi bakau, tidak membuang sampah dan limbah rumah tangga ke laut serta mengurangi kegiatan memancing di dekat tumbuhan bakau. 


\section{DAFTAR PUSTAKA}

Amin, B. 2001. Akumulasi dan Distribusi Logam Berat $\mathrm{Pb}$ dan $\mathrm{Cu}$ pada Mangrove (Avicennia marina) di Perairan Pantai Dumai, Riau.Jurnal Natur Indonesia Vol. 4(1): 80-86.

Cutra, Samil (2013). Akumulasi Logam Berat Timbal (Pb) dan Cadmium (Cd) Pada Pohon Mangrove (Avicennia marina) di Perairan Mangrove Karangsong, Indramayu. Skripsi. Bogor: IPB Darmono, 1995. Logam dalam Sistem Makhluk Hidup. UI Press. Jakarta.

Darmono. 2010. Lingkungan Hidup dan Pencemaran: Hubungan dengan Toksikologi Senyawa Logam. UI Press, Jakarta.

Hamzah, F dan Setiawan, A. 2010. Akumulasi Logam Berat Pb, Cu, dan Zn, di Hutan Mangrove Muara Angke, Jakarta Utara. Jurnal Ilmu dan Teknologi Kelautan Tropis. Vol 2: $41-51$

Ika, T., Said, I., 2011. Analisis Logam Timbal (Pb) dan Besi (Fe) dalam Air Laut di Wilayah Pesisir Pelabuhan Ferry Taipa kecamatan Palu Utara. Jurnal Akademi Kimia, 1(4): 181186.

Purba, Desi Monalisa. 2017. Pemeriksaan Kandungan Mineral Natrium, Kalsium Dan Tembaga Pada Wortel (Daucus carota L.) Secara Spektrofotometri Serapan Atom. Skripsi. Universitas Sumatra Utara. Medan.

Rochyatun, E., M.T. Kaisupy, dan A. Rozak. 2006. Distribusi Logam Berat dalam Air dan Sedimen di Perairan Muara Sungai Cisadane. Makara Sains, 10(1): 35-40.

Setiawan, Heru (2013). Akumulasi dan Distribusi Logam Berat Pada Vegetasi Mangrove Di Perairan Pesisir Sulawesi Selatan. Jurnal Ilmu Kehutanan Vol. VII No. 1. 